Forum 2019 · 34:132

https://doi.org/10.1007/s12312-019-0587-4

Online publiziert: 21. Februar 2019

(c) Springer Medizin Verlag GmbH, ein Teil von

Springer Nature 2019

\section{German Cancer Survivors Day 2019}

\section{Ankündigung}

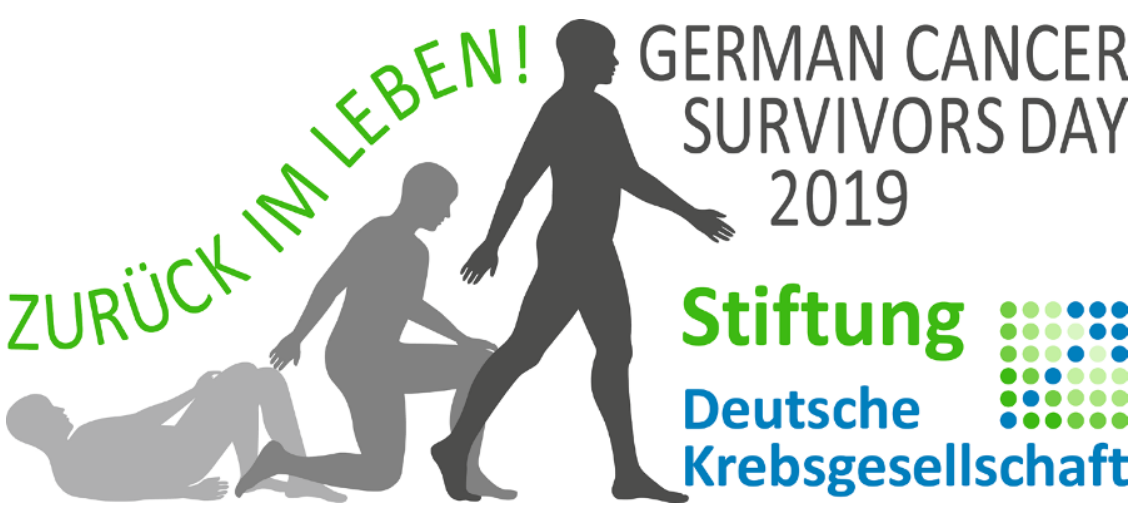

sein. Die Pausen gestalten Teilnehmer des Poetry-Slams „Sprich mit mir! Über Krebs“ und die „Bewegten Frauen“. Auf dem Programm stehen unter anderem die Themen Familie und Alltag, Kinder und Krebs, Krebs in der Verwandtschaft, Psychische Belastungen, Sexualität und Kinderwunsch, Gesundheits-Apps sowie Freizeit und Reisen. Die Teilnahme am GCSD ist kostenlos. Die Stiftung bietet einen Bus-Shuttle von Rostock, Magdeburg, Chemnitz, Leipzig und Er- furt an. Das vollständige Programm ist hier zu finden: www.deutsche-krebsstiftung.de.

\section{Korrespondenzadresse}

Iris Meumann

Deutsche Krebsstiftung, c/o Deutsche Krebsgesellschaft

Kuno-Fischer-Straße 8, 14057 Berlin,

Deutschland

meumann@deutsche-krebsstiftung.de 